\title{
PENGARUH AGING PADA KEKUATAN TARIK (TENSILE STRENGTH) FILM LATEKS KARET ALAM BERPENGISI NANOKRISTALIN SELULOSA DAN PENYERASI ALKANOLAMIDA
}

\author{
Marfuah Lubis, Nuim Hayat, Hamidah Harahap \\ Departemen Teknik Kimia, Fakultas Teknik, Universitas Sumatera Utara \\ Jl. Almamater Kampus USU, Medan, 20155, Indonesia \\ Email: marfuah_lubis@yahoo.co.id
}

\begin{abstract}
Abstrak
Nanokristalin selulosa merupakan pengisi berukuran nano dengan kristalinitas yang tinggi dan diperoleh melalui proses hidrolisis alfa selulosa dari ampas tebu. Pengujian kekuatan tarik film lateks karet alam berpengisi nanokristalin selulosa dan penyerasi alkanolamida setelah perlakuan aging telah dilakukan. Film lateks karet alam dibuat melalui metode pencelupan berkoagulan dan diikuti dengan proses vulkanisasi pada suhu $100{ }^{\circ} \mathrm{C}$ selama 20 menit. Perlakuan aging film lateks karet alam dilakukan pada suhu $70{ }^{\circ} \mathrm{C}$ selama 24 jam. Hasil uji kekuatan tarik film lateks karet alam yang diperoleh menunjukkan bahwa nilai kekuatan tarik film lateks karet alam berpengisi nanokristalin selulosa setelah aging lebih rendah dibandingkan nilai kekuatan tarik film lateks karet alam sebelum aging. Namun, nilai kekuatan tarik film lateks karet alam berpengisi nanokristalin selulosa dan dimodifikasi alkanolamida setelah aging lebih tinggi dibandingkan nilai kekuatan tarik film lateks karet alam sebelum aging.
\end{abstract}

Kata kunci : Lateks karet alam, nanokristalin selulosa, alkanolamida, aging, vulkanisasi.

\begin{abstract}
Nanocrystalline cellulose is nano sized filler with high crystallinity and obtanained by hydrolysis of alpha cellulose from sugarcane bagasse. Tensile test of natural rubber latex film filled nanocrystalline cellulose and alkanolamide as compatibilizer after aging treatment have been done. Natural rubber latex films were prepared by coagulant dipping method and followed by vulcanization process at temperature $100^{\circ} \mathrm{C}$ and 20 minutes. Aging treatment of natural rubber latex films have done at temperature $70^{\circ} \mathrm{C}$ for 24 hours. Tensile test result of natural rubber latex filled nanocrystalline cellulose showed the tensile strength value of aged natural rubber latex film were lower than unaged one. However, tensile strength value of aged natural rubber latex film filled nanocrystalline cellulose modified alkanolamide were higher than unaged film.
\end{abstract}

Keyword : Natural rubber latex, nanocrystalline cellulose, alkanolamide, aging, vulcanization.

\section{Pendahuluan}

Lateks karet alam merupakan salah satu hasil pertanian terkemuka karena banyak menunjang perekonomian negara dengan total produksi 3,205 juta ton pada tahun 2014 [9]. Produk lateks karet alam umumnya memiliki beberapa kelemahan seperti polimer yang lain diantaranya rentan terhadap oksidasi atau degradasi akibat panas dan kekuatan mekanik yang rendah, terutama setelah dibentuk menjadi film tipis. Oleh sebab itu, dalam pengolahannya perlu ditambahkan penguat seperti pengisi (filler) baik berupa pengisi anorganik maupun pengisi organik. Penguat pada lateks karet alam terutama digunakan untuk meningkatkan kekuatan, ketahanan abrasi, kekerasan, kekuatan tarik, stabilitas termal dan modulus [14].

Selulosa merupakan salah satu contoh pengisi organik paling potensial karena merupakan polimer alam dengan jumlah yang melimpah dan memiliki sifat-sifat unggul seperti densitas rendah, kaku dan biodegradable. Oleh karena sifat tersebut, selulosa merupakan bahan baku yang menjanjikan untuk dijadikan pengisi organik [5].

Salah satu sumber selulosa yang paling potensial adalah ampas tebu. Ampas tebu merupakan limbah padat dari pengolahan industri gula tebu yang yang jumlahnya berlimpah di Indonesia serta volumenya mencapai $30-40 \%$ dari tebu giling. Saat ini perkebunan tebu rakyat mendominasi luas areal perkebunan tebu di Indonesia [2]. Ampas tebu terdiri atas selulosa 43,6\%, hemiselulosa $33,8 \%$, lignin $18,1 \%$, abu 2,3\% dan lilin $0,8 \%$ dengan basis berat kering [6]. 
Dalam penyimpanan atau pemakaian produk lateks karet alam seringkali terjadi perubahan pada sifat mekanik dan kualitas produk yang disebabkan oleh beberapa hal seperti panas, aktivitas mikroba, cahaya, kelembapan dan lain lain [10;13]. Salah satu hal yang paling signifikan atas perubahan sifat mekanik maupun kualitas produk disebabkan oleh panas yang terkena pada produk dalam waktu yang lama atau aging.

Dalam penelitian ini digunakan nanokristalin selulosa sebagai pengisi dan alkanolamida sebagai penyerasi dengan tujuan agar interaksi antara pengisi dan lateks karet alam dapat terjadi dengan baik sehingga diharapkan akan meningkatkan sifat mekanik dan sifat ketahanan akibat aging film lateks karet alam yang dihasilkan.

\section{Teori}

Lateks karet alam adalah cairan berwana putih kekuningan yang diperoleh dari pohon karet (Havea brasiliensis) dan merupakan makro molekul poliisoprena dengan konfigurasi struktur molekulnya yaitu cis-1,4poliisoprena dan memiliki kelenturan rantai molekul yang tinggi [11]. Dalam proses pembuatan barang jadi, cairan lateks harus dibuat menjadi kompon lateks yang cair (compounding) yang umumnya mengandung enam atau lebih bahan kimia karet tergantung karakteristik produk karet yang diinginkan, seperti bahan pemvulkanisasi (vulcanizing agent), pencepat vulkanisasi (accelerator), penggiat (activator), antioksidan, pemantap (stabilizer), pengisi (filler) dan penyerasi (compatibilizer) [8].

Proses utama pembuatan produk lateks adalah vulkanisasi. Vulkanisasi merupakan proses pemanasan karet setelah dicampur dengan sulfur. Proses vulkanisasi bertujuan untuk membentuk polimer karet yang saling bertautan satu sama lain (cross-linking) sehingga meningkatkan properties dari produk lateks yang dihasilkan [8]

Bahan pengisi merupakan bahan yang paling banyak kedua dalam hal kuantitas dalam suatu campuran lateks setelah lateks itu sendiri. Berdasarkan sumbernya, bahan pengisi dapat berupa bahan pengisi anorganik (kalsium karbonat, barit dan silika) dan bahan pengisi organik (serat, resin fenolik, karet alam siklik, dll.) Pengisi harus memiliki ukuran partikel yang kecil <1000 nm untuk mendapatkan efek penguatan yang baik. Efek penguatan yang baik disebabkan ukuran pengisi yang kecil akan meningkatkan permukaan yang aktif secara kimia dan permukaan yang berpori baik dan sangat teratur bentuknya untuk memaksimalkan kontak antara karet dan pengisi [7].

Aging adalah fenomena umum yang terjadi pada elastomer alami dan sintetik berupa penurunan sifat yang tidak diinginkan selama penyimpanan ataupun penggunaan. Berbagai perubahan dapat terjadi pada suatu komponen elastomer sebagai hasil dari kondisi dimana elastomer tersebut disimpan atau digunakan. Proses aging karet alam sangat kompleks, namun diketahui bahwa oksidasi adalah proses degradasi yang signifikan [4] Salah satu metode paling umum digunakan untuk aging dipercepat adalah menggunakan oven dimana sampel karet, umumnya dalam bentuk dumb-bells, digantungkan pada aliran udara bebas pada berbagai temperatur dan periode waktu tertentu. Sifat yang diukur adalah kekuatan tarik, pemanjangan saat patah, modulus dan kekerasan. Hasil yang didapat dapat memberikan gambaran estimasi untuk penyimpan yang aman dalam jangka waktu tertentu [15].

\section{Metodologi Penelitian \\ Bahan}

Ampas tebu diperoleh dari limbah penjual sari tebu lokal Medan Sumatera Utara. $60 \%$ high ammonia latex yang diperoleh dari toko lokal daerah Medan. Bahan kuratif lateks karet alam seperti sulfur, zink oksida $(\mathrm{ZnO})$, zinc diethyldithiocarbamate (ZDEC) dan antioksidan (AO) diperoleh dari Farten Technique (M) Sdn. Bhd., Pulau Penang, Malaysia. Bahan bahan lain seperti asam nitrat $\left(\mathrm{HNO}_{3}\right)$, natrium nitrit $\left(\mathrm{NaNO}_{2}\right)$, natrium hidroksida $(\mathrm{NaOH})$, natrium sulfit $\left(\mathrm{Na}_{2} \mathrm{SO}_{3}\right)$, natrium hipoklorit $(\mathrm{NaOCl})$, hidrogen peroksida $\left(\mathrm{H}_{2} \mathrm{O}_{2}\right)$, asam sulfat $\left(\mathrm{H}_{2} \mathrm{SO}_{4}\right)$, kalium hidroksida $(\mathrm{KOH})$, asam asetat $\left(\mathrm{CH}_{3} \mathrm{COOH}\right)$, kalsium nitrat tetrahidrat $\left(\mathrm{Ca}\left(\mathrm{NO}_{3}\right)_{2} \cdot 4 \mathrm{H}_{2} \mathrm{O}\right)$, toluene $\left(\mathrm{C}_{6} \mathrm{H}_{5} \mathrm{CH}_{3}\right)$, kloroform $\left(\mathrm{CHCl}_{3}\right)$ dan alkanolamida juga turut digunakan dalam penelitian ini.

\section{Penyediaan Nanokristalin Selulosa}

Selulosa diekstrak dari limbah ampas tebu dengan beberapa tahapan. Pertama dilakukan proses delignifikasi terhadap ampas tebu yang telah disiapkan, pada proses 
delignifikasi, 75 gram ampas tebu reaksikan dengan 1 liter larutan $\mathrm{HNO}_{3}$ 3,5\% dan $10 \mathrm{mg}$ $\mathrm{NaNO}_{2}$ Pada temperatur $90{ }^{\circ} \mathrm{C}$. Setelah itu selulosa di bleach dengan menggunakan 250 $\mathrm{ml} \mathrm{NaOCl} 1,75 \%$ temperatur mendidih selama 30 menit. Selanjutnya dilakukan pemurnian alfa selulosa dengan mereaksikan selulosa dengan $17,5 \% \mathrm{NaOH}$ pada $80{ }^{\circ} \mathrm{C}$ selama 0,5 jam.

Nanokristalin selulosa disiapkan dengan hidrolisis asam menggunakan asam sulfat $45 \%$ terhadap alfa selulosa yang diperoleh dari limbah ampas tebu tersebut. Kemudian dilanjutkan dengan ultrasonikasi dan pemisahan dengan membran dialisis[3].

\section{Pembuatan Film Lateks Karet Alam}

Pengisi dengan $10 \%$ nanokristalin selulosa disiapkan dengan mendispersikan nanokristalin selulosa, air, dan alkanolamida menggunakan ball mill dengan komposisi tertera pada tabel 1 .

Tabel 1. Formulasi Larutan Dispersi Nanokristalin Selulosa dan Alkanolamida

\begin{tabular}{|l|l|l|}
\hline \multicolumn{1}{|c|}{ Bahan } & \multicolumn{2}{c|}{ Persentase (\%) } \\
\hline Nanokristalin selulosa & 10 & 10 \\
\hline Alkanolamida & 0 & 2,5 \\
\hline Air & 90 & 87,5 \\
\hline
\end{tabular}

Dispersi pengisi kemudian dicampur dengan kuratif dan lateks karet alam (kompon lateks) pada proses pravulkanisasi. Proses pravulkanisasi dilakukan pada temperatur 70 ${ }^{\circ} \mathrm{C}$ untuk mencapai tingkat kematangan yang diinginkan. Proses prevulkanisasi dinyatakan selesai ketika uji kloroform telah mencapai tingkat 3. Tabel 2 memperlihatkan Formulasi dari kompon lateks karet alam.

Setelah pravulkanisasi sistem lateks selesai, campuran dibiarkan selama 24 jam hingga gelembung yang terbentuk hilang. Apabila tidak ada lagi gelembung yang terbentuk, kompon dicetak dengan metode pencelupan berkoagulan (coagulant dipping method), setelah itu dilakukan vulkanisasi pada temperatur $100{ }^{\circ} \mathrm{C}$ selama 20 menit. Setelah divulkanisasi plat didinginkan dan film lateks karet alam dilepaskan dari plat. Film lateks yang dihasilkan kemudian dimasukkan ke dalam oven dan dipanaskan pada suhu $70{ }^{\circ} \mathrm{C}$ selama 24 jam untuk perlakuan aging.
Tabel 2. Formulasi Kompon Lateks Karet Alam

\begin{tabular}{|l|c|}
\hline \multicolumn{1}{|c|}{ Bahan } & Kadar (bsk) \\
\hline $60 \%$ High Ammonia Latex & 100 \\
\hline $50 \%$ Larutan Sulfur & 1,8 \\
\hline $50 \%$ Larutan ZDEC & 1,8 \\
\hline $30 \%$ Larutan ZnO & 0,5 \\
\hline $50 \%$ Larutan Antioksidan & 1,2 \\
\hline $10 \%$ Larutan KOH & 1,8 \\
\hline $\begin{array}{l}10 \% \text { Larutan Dispersi } \\
\text { Nanokritalin Selulosa dan } \\
\text { Alkanolamida }\end{array}$ & $0 ; 5 ; 10 ; 15$ \\
\hline
\end{tabular}

\section{Uji Kekuatan Tarik Film Lateks Karet Alam}

Spesimen film lateks karet alam dipotong dalam bentuk dumbble-shaped sesuai dengan ASTM D 412. Uji kekuatan tarik dilakukan menggunakan mesin Instron model 3366 dengan kecepatan $500 \mathrm{~mm} /$ menit pada suhu ruangan.

\section{Hasil dan Pembahasan}

Nanokristalin selulosa yang digunakan memiliki bentuk tabung (rod shape) dan merupakan hasil dari hidrolisis asam alfa selulosa dari ampas tebu dan memiliki diameter 40-160 nm serta panjang hingga ratusan $\mathrm{nm}$. Kristalinitas nanokristalin selulosa cukup tinggi yaitu 92,33 \%. Indeks kristalinitas yang tinggi mengindikasikan bahwa hemiselulos dan lignin yang ada pada bagian amorf selulosa berhasil dipisahkan dari bagian kristalin selulosa melalui hidrolisis asam. Kristalinitas selulosa yang tinggi lebih efektif untuk menghasilkan bahan dengan kualitas yang baik dan memiliki nilai kekuatan yang tinggi.

Nilai kekuatan tarik film lateks karet alam berpengisi nanokristalin selulosa setelah aging ditunjukkan oleh gambar 1. Gambar 1 menunjukkan bahwa nilai kekuatan tarik film lateks karet alam berpengisi nanokristalin selulosa tanpa penyeras alkanolamida setelah aging lebih rendah dibandingkan dengan nilai kekuatan tarik sebelum aging untuk semua variasi pembebanan pengisi, namun, nilai kekuatan tarik film lateks karet alam ini masih tergolong tinggi. Umumnya, kekuatan tarik suatu material akan menurun setelah perlakuan aging. Gambar 1 menunjukkan bahwa penurunan nilai kekuatan tarik film lateks karet alam setelah perlakuan aging tidak signifikan. Hal ini disebabkan karena nanokristalin selulosa sebagai pengisi mampu 
meningkatkan ketahanan film lateks karet alam terhadap panas. Nanokristalin selulosa merupakan pengisi dengan gugus fungsi polar. Kehadiran gugus fungsi polar pada matriks karet dapat meningkatkan ketahanan aging pada komposit karet [1].

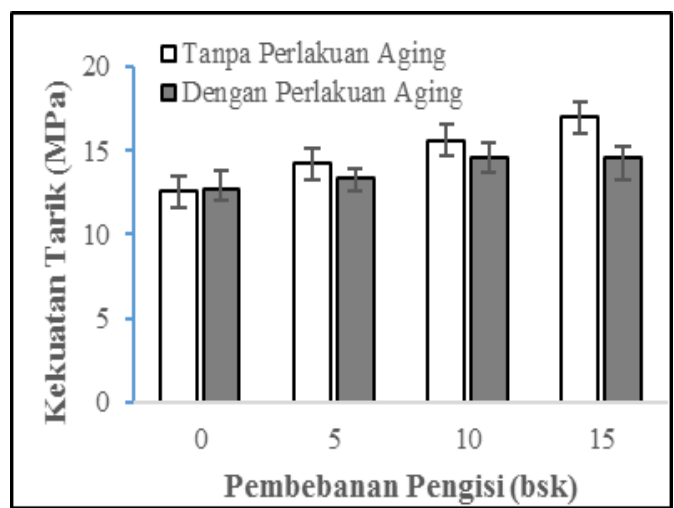

Gambar 1. Kekuatan Tarik (Tensile strength) Film Lateks Karet Alam Bepengisi Nanokristalin Selulosa

Sifat yang baik ini disebabkan karena kekakuan tinggi dari selulosa yang menyebabkan kekuatan semakin tinggi dan reaktivitas tinggi dari selulosa Nanokristalin selulosa memiliki dimensi skala nano dan rasio panjang dan lebar yang besar (aspect ratio) sehingga meningkatkan luas permukaan antarmuka (interface) antara lateks karet alam dengan nanokristalin selulosa [12]. Interaksi antarmuka yang baik menyebabkan pengisi lebih mudah terdispersi di dalam lateks karet alam. Hal ini menyebabkan lateks dapat mentransfer panas dengan baik kepada nanokristalin selulosa dan mengurangi efek penurunan sifat akibat aging.

Nilai kekuatan tarik film lateks karet alam berpengisi nanokristalin selulosa dan penyerasi alkanolamida setelah aging ditunjukkan oleh gambar 2. Gambar 2 menunjukkan perilaku film lateks karet alam dengan penyerasi alkanolamida yang berlawanan dengan film lateks karet alam tanpa penyerasi alkanolamida pada gambar 1, yaitu nilai kekuatan tarik film lateks karet alam dengan penyerasi alkanolamida setelah aging lebih tinggi dibandingkan kekuatan tarik sebelum aging.

Penambahan alkanolamida memberikan pengaruh yang besar pada ketahanan film lateks karet alam terhadap aging. Peningkatan nilai kekuatan tarik setelah aging sangat berhubungan dengan kemampuan alkanolamida untuk meningkatkan interaksi antara nanokristalin selulosa dengan lateks karet alam.

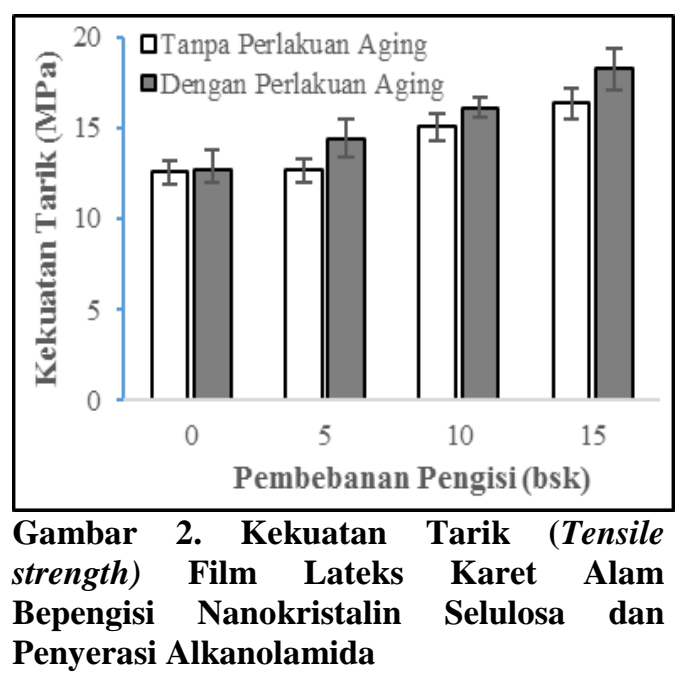

Alkanolamida bekerja dengan memodifikasi permukaan nanokristalin selulosa yang hidrofilik dan tidak sesuai dengan lateks karet alam yang hidrofobik dan umumnya memiliki interaksi yang rendah. Nanokristalin selulosa yang telah dimodifikasi ini bersifat hidrofobik dan dapat menghasilkan interaksi yang kuat dengan lateks karet alam. Interaksi yang kuat akan mempercepat laju pematangan dan memungkinkan terjadinya proses pematangan dan pembentukan ikatan sambung silang lanjutan (post-curing) lateks karet alam akibat pemberian panas pada saat aging berlangsung.

\section{Kesimpulan}

Nanokristalin selulosa merupakan contoh pengisi organik yang memiliki sifat penguatan yang baik terhadap film lateks karet alam setelah aging. Penambahan jumlah pembebanan pengisi meningkatkan kemampuan film lateks karet alam dalam menahan efek penurunan kualitas akibat aging. Alkanolamida dapat meningkatkan interaksi antara lateks karet alam dan nanokristalin selulosa sehingga mampu meningkatkan nilai kekuatan tarik film lateks karet alam setelah perlakuan aging.

\section{Daftar Pustaka}

[1] Arayapranee, W dan Rempel, G. L, Effects of polarity on the filler-rubber interaction and properties of silica filled grafted natural rubber composites, Journal of Polymers, Volume 2013, Article ID 279529, p. 1-9, 2013. 
[2] Arioen, Refi, Kajian perlakuan awal secara basa dan enzimatis untuk menghidrolisis ampas tebu menjadi gula reduksi, Tesis, Universitas Lampung, Lampung, 2011.

[3] Aulia, F., Marpongahtun dan Gea, S., Studi penyediaan nanokristal selulosa dari tandan kosong sawit (TKS), Jurnal Saintia Kimia, Vol. 1, No. 2, 2013.

[4] Azura, A.R., Ghazali, S. dan Mariatti, M., Effects of the filler loading and aging time on the mechanical and electrical conductivity properties of carbon black filled natural rubber, Journal of Applied Polymer Science, Vol. 110, p. 747-752, 2008.

[5] Chen, D., Biocomposites reinforced with cellulose nanocrystals derived from potato peel waste, Thesis, Mc Master University, Hamilton, 2012.

[6] Correa, J.L., Vela, A.F., Grimaldo, D.O. dan Delgado, J.B., Experimental evaluation of sugar cane bagasse storage in bales system, Journal of Applied Research and Technology, Vol. 8, p. 365-377, 2010.

[7] Egwaikhide, A. P., Okleimen, F.E., and Lawal. U., Rheological and mechanical properties of natural rubber compound filled with carbonized palm kernel husk and carbon black, Science Journal of Chemistry, Vol.1, No. 5, p.50-55, 2013.

[8] Fachry, A. R., Sari, T. I., Putra, B.A. dan Kristianto, D.A, Pengaruh penambahan filler kaolin terhadap elastisitas kekerasan produk souvenir dari karet alam (havea brasiliensis), Prosiding SNTK TOPI, Pekanbaru, 2012.

[9] GAPKINDO, Rubber production in Indonesia, www.gapkindo.org. Diakses pada 3 September 2015.

[10] Hashim, A. dan Ikram A, Enviromental advantage of natural rubber latex products, Rubber Research Institute of Malaysia, 2003.

[11] Hulu, Temali, Pengaruh ekstrak nenas (Ananas sativus) sebagai koagulan terhadap kualitas lembaran karet, Tesis, Universitas Sumatera Utara, Medan, 2013.

[12] Mariano, Marcos., Kissi, Nadia El., and Dufresne, Alain, Cellulose nanocrystals and related nanocomposites: review of some properties and challenges, Journal of Polymer Science, Part B: Polymer Physics, Vol. 00, p. 1-16, 2014.
[13] Neiman, M. B, Aging and stabilization of polymers, Consultants Bureau Publisher, New York, 1965.

[14] On, N. K., Rashid, A.A., Nazlan, M. M. M. and Hamdan, H., Thermal and mechanical behaviour of natural rubber latex-silica aerogel film, Journal of Applied Polymer Science, Vol. 124, p. 3108-3116, 2011.

[15] Stokoe, A.L, Heat ageing of rubbers, National Technical Information Service, England, p.1, 1972. 